\title{
INTERMEDIATE WATER FORMATION AT THE JAPAN/EAST SEA SUBPOLAR FRONT
}

BY CRAIG M. LEE, LEIF N. THOMAS, AND YUTAKA YOSHIKAWA

Upper-ocean fronts play an important role in determining upper pycnocline water properties by providing an efficient conduit for communicating atmospheric forcing into the stratified interior. Mesoscale fronts exhibit strong lateral contrasts at $1-10-\mathrm{km}$ scales, with large frontal density gradients supporting intense, largely geostrophic, surface-trapped jets. Instabilities associated with these strong flows can radiate near-inertial internal waves and produce to as "subduction." In the global ocean, subduction imprints wintertime mixedlayer properties on a vertically homogenous layer embedded within the upper pycnocline. Termed "mode water," these layers often extend over large regions, impacting pycnocline structure and thus playing an important role in determining large-scale circulation. The potential importance of frontal subduction has motivated numerous observational (e.g., Pollard and Regier, 1992; Rudnick and

\section{The Japan/East Sea offers an exceptional}

\section{laboratory for investigating strongly forced upper-ocean fronts.}

eddies, making frontal-zone regions of energetic, small-scale activity. These instabilities, modulated by atmospheric forcing (e.g., by strong winds, surface buoyancy loss) can also produce strong vertical exchanges that rapidly inject weakly stratified mixed-layer waters into the pycnocline, a process referred
Luyten, 1996; Joyce et al., 1998) and numerical (Spall, 1995; Spall et al., 2000) studies that provide significant insight into frontal dynamics during weak forcing. Although wintertime subduction drives significant mode-water formation, difficulties associated with collecting high-resolution measurements in demanding wintertime conditions complicate observational efforts. This article summarizes recent efforts to understand how fronts respond to intense wind and buoyancy forcing.

The Japan/East Sea offers an exceptional laboratory for investigating strongly forced upper-ocean fronts. The Asian landmass and Japanese islands bound the 3700-m deep marginal sea, which communicates with the Pacific through shallow Tsushima (south) and Tsugaru (east) Straits, and with the Okhotsk Sea through the Soya and Mamiya Straits. Warm, saline Kuroshio waters enter Tsushima Strait to form the Tsushima Warm Current, with one branch flowing northward along the Korean coast to meet the south-flowing North Korean (Liman) Cold Current (Figure 1; see also Talley et al., this issue, Figure 1). The confluence of these two water masses forms the Japan/East Sea Subpolar Front, which extends across the basin at roughly $40^{\circ} \mathrm{N}$ to exit Tsugaru Strait along the eastern margin.

Sharp density contrasts across the front support a surface-intensified jet 


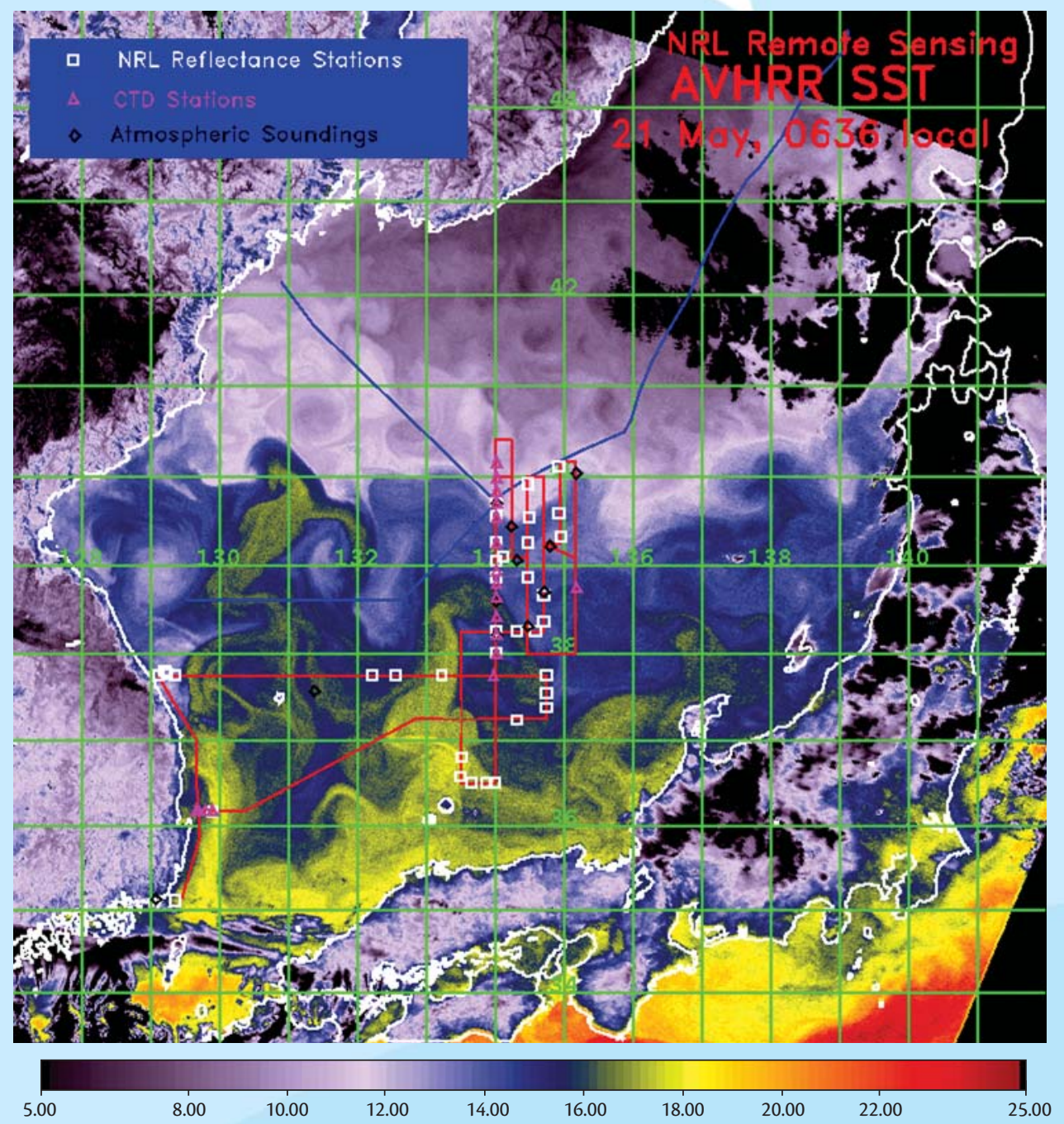

Figure 1. AVHRR sea surface temperature image taken on May 21, 1999, during the springtime R/V Roger Revelle SeaSoar cruise. The red line marks the SeaSoar survey track, while symbols indicate the location of other measurements. The Subpolar Front extends across the basin between $39^{\circ} 30^{\prime} \mathrm{N}$ and $40^{\circ} \mathrm{N}$. Note the multiple paths followed by the Tsushima Warm Current after it enters the Japan/East Sea through Tsushima Strait. Courtesy of R. Arnone, Naval Research Laboratory, Stennis Space Center.

with lateral scales of $\mathrm{O}(10 \mathrm{~km})$ and speeds exceeding $0.5 \mathrm{~m} \mathrm{~s}^{-1}$. During spring and summer, modest solar warming under light winds produces a warm, stratified surface layer that caps the front, reducing north-south surface density contrasts, although strong subsurface gradients remain. Strong lateral gradi- ents (sea surface temperature changes of $5^{\circ} \mathrm{C}$ over $5 \mathrm{~km}$ ), energetic small-scale activity, and deep mixed layers typify wintertime conditions at the Subpolar Front. During winter, dry, cold continental air masses periodically channel through mountain gaps near Vladivostok to drive intense, northwesterly winds over the northern and central Japan/East Sea (Kawamura and Wu 1998; Dorman et al., 2004; Scotti, 2005). These "cold-air outbreaks" manifest as relatively narrow wind-jets that can drive large buoyancy loss and large near-surface Ekman flows at the Subpolar Front (Figure 2). This combination of strong forcing over an 


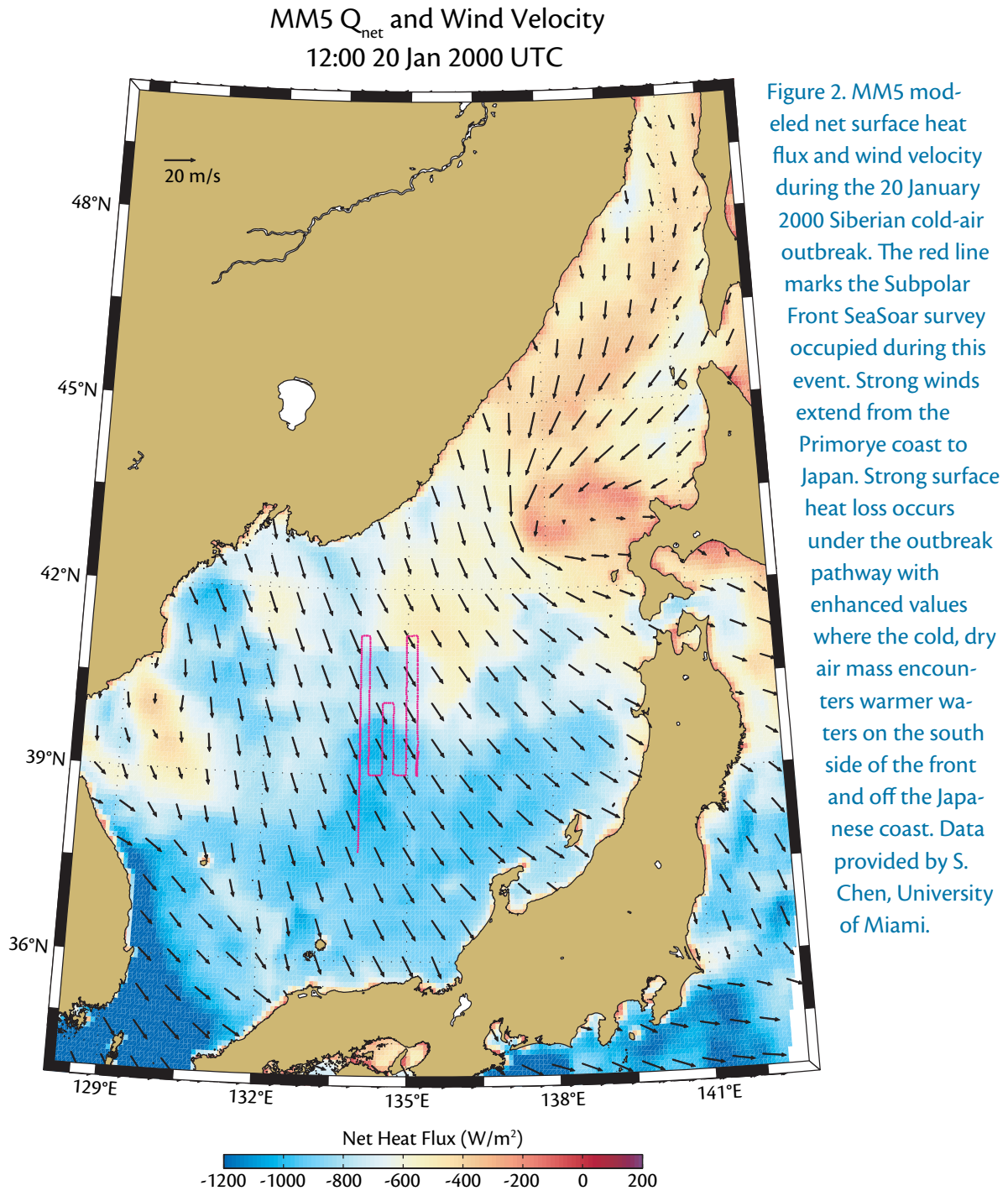

intense, narrow front gives rise to instabilities that can dramatically enhance vertical exchange rates. The presence of a persistent, strong subpolar front; intense, episodic (but reliable) atmospheric forcing by cold-air outbreaks; and relatively easy logistics makes the Japan/East Sea an ideal location for investigating the dynamics of fronts, subduction, and water-mass-formation processes.

Previous investigations characterized subpolar front seasonal variability and traced subsurface water masses to formation regions at the front. Talley et al. (this issue) characterize the basin's gen- eral circulation and water-mass properties, illustrating the large-scale impacts of subpolar front water-mass formation and subduction. Remotely sensed sea surface temperature (e.g., Isoda et al., 1991; Isoda, 1994; Park et al., 2004) revealed strong cross-front gradients in winter and spring, with large meanders in the western basin and strong bathymetric steering over the Yamato Rise constraining the pathway to the east. Kajiura (1958) provided an early classification of Japan/East Sea water masses that recognized a fresh, cool intermediate water with elevated dissolved oxygen concentrations found near the base of the pycnocline south of the front. Kim and Chung (1984) labeled this "East Sea Intermediate Water" and speculated that it might originate through subduction at the Subpolar Front. Numerical studies (Yoshikawa et al., 1999; Yoshikawa et al., 2001; Yoon and Kawamura, 2002) suggest that these intermediate waters originate along the Primorye coast with the entrainment of fresh Amur River outflow into the Liman Cold Current. The resulting water mass eventually flows eastward along the northern side of the Subpolar Front, where wintertime subduction carries it into the pycnocline. Gordon et al. (2002) found large (100 km), thick (> $100 \mathrm{~m}$ ) eddies embedded in the pycnocline at several locations south of the front. Water properties suggest that these eddies originated in the wintertime mixed layer of the Subpolar Front and are perhaps the integrated result of wintertime forcing and subduction. These prominent, persistent features influence basin-scale circulation and provide an illustration of the large-scale impacts of subduction processes active at the $\mathrm{O}(10 \mathrm{~km})$ scales of upper ocean fronts.

Supported by the U.S. Office of Naval Research, an international science team conducted an intensive measurement

Craig M. Lee (craig@apl.washington.edu) is Senior Oceanographer, Applied Physics Laboratory, University of Washington, Seattle, WA, USA. Leif $\mathbf{N}$. Thomas is Assistant Scientist, Department of Physical Oceanography, Woods Hole Oceanographic Institution, Woods Hole, MA, USA. Yutaka Yoshikawa is Associate Professor, Research Institute for Applied Mechanics, Kyushu University, Fukuoka, Japan. 
program directed at documenting and understanding how mesoscale fronts respond to strong atmospheric forcing in the wintertime Japan/East Sea. Repeated, quasi-synoptic, high-resolution, three-dimensional surveys of physical (temperature, salinity, velocity) and biooptical variables documented frontal evolution during and after strong forcing events. This study benefited greatly from the availability of real-time remote sensing and detailed meteorological forecasts that enabled an adaptive sampling strategy aimed at focusing intense, repeated surveys on selected frontal segments during periods of intense forcing. Meteorological sampling included extensive shipboard sensors measuring wind velocity, relative humidity, barometric pressure, air temperature, and radiative fluxes (Dorman et al., 2004). Additional measurements included hydrographic sampling for chemical and biological properties, rounding out a tightly coordinated, interdisciplinary measurement program. A companion cruise sampled springtime conditions, characterizing the integrated effects of the previous winter's forcing. Sampling centered on a towed, undulating profiler, "SeaSoar" (Figure 3), that profiles repeatedly from the ocean surface to roughly $350-\mathrm{m}$ depth while being towed at 8 knots. This configuration provides 3 -km along-track profile separation, sufficient to resolve smallscale motions associated with subduction processes, while moving rapidly enough to provide a quasi-synoptic "snapshot" of a three-dimensional segment of the Subpolar Front. SeaSoar carried sensors for measuring temperature, conductivity (salinity), dissolved oxygen, light transmission, chlorophyll fluorescence, optical backscatter, and optical attenuation and absorption. When combined with meteorological measurements and velocity profiles collected using the shipboard Acoustic Doppler Current Profiler mounted aboard R/V Roger Revelle, these observations provide direct evidence of wintertime frontal subduction.

\section{ATMOSPHERIC FORCING}

Wintertime outbreaks of very cold, dry Siberian air produce intense south/ southeastward winds and large oceanic net surface heat loss across much of the Japan/East Sea (Figure 4). Outbreaks occur frequently between December and February, typically lasting 1-3 days with effects that can reach across the entire basin. Dorman et al. (2004) noted that during 1991-2002, cold-air outbreaks occupied 39 percent of the DecemberFebruary period and accounted for 43 percent of the net heat loss, suggesting that their integrated effect plays a central role in forcing the Japan/East Sea. Mountain gaps along the Primo-

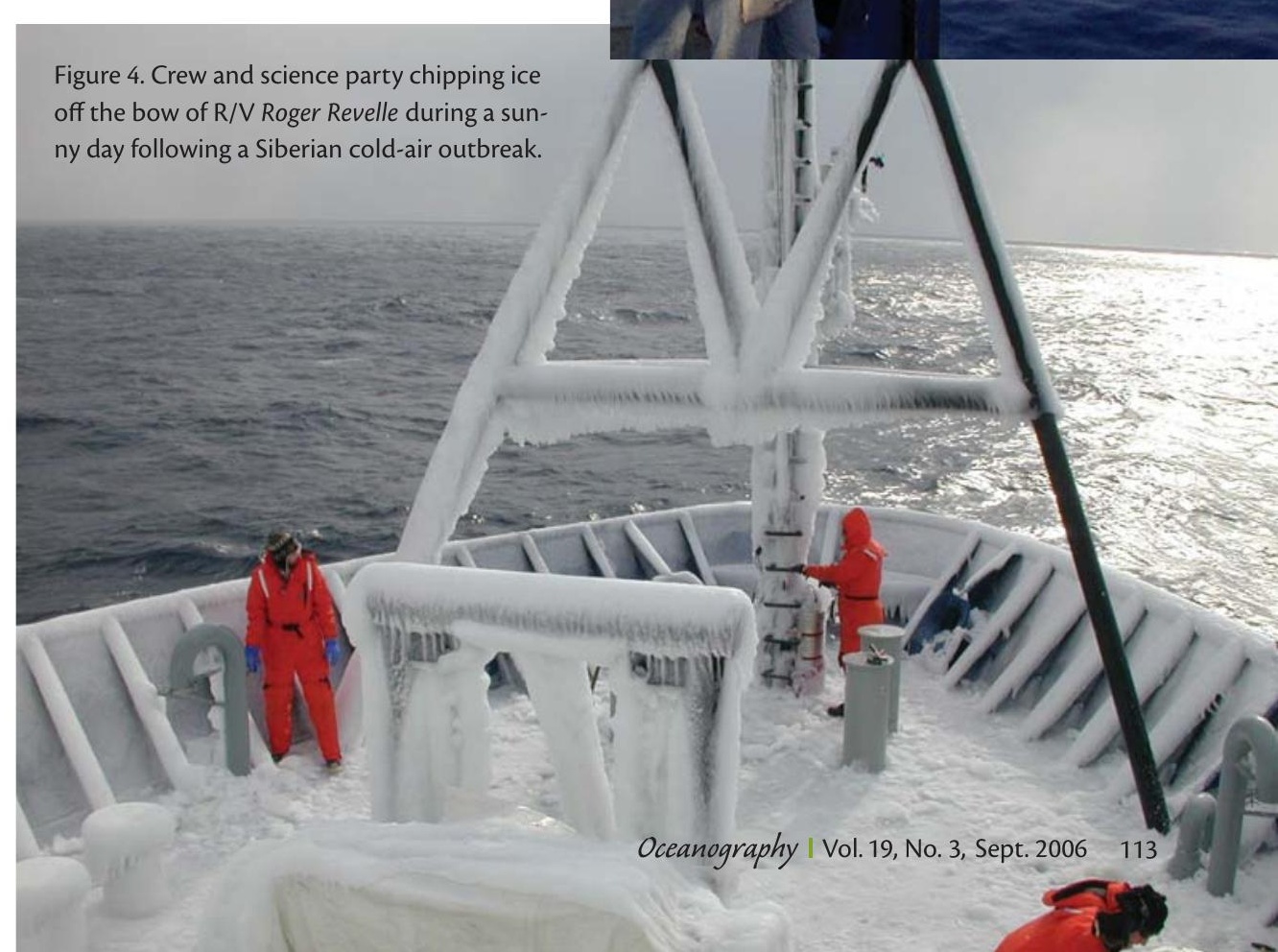

rye coast channel outbreaks into strong jets that extend offshore from Vladivostok to the Japanese coast (Figure 2 and Scotti, 2005). The Subpolar Front can experience wind speeds exceeding $25 \mathrm{~m} \mathrm{~s}^{-1}$ with strong lateral shears, typi-

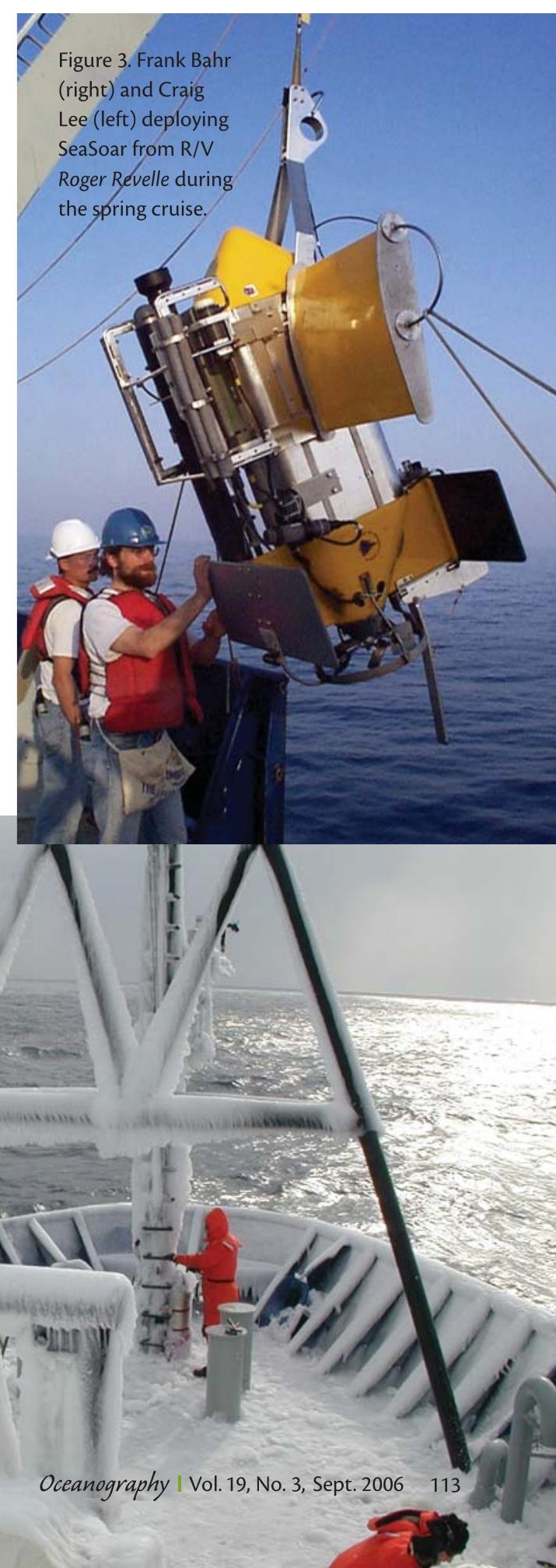


cally oriented such that the winds have a significant component in the direction of the frontal jet. As the next section describes, these winds allow Siberian cold- air outbreaks to efficiently drive vertical exchanges at the front. Latent and sensible heat loss dominate the net surface heat flux. The largest losses occur south

(a) JANUARY-FEBRUARY 2000 JES SEASOAR CRUISE
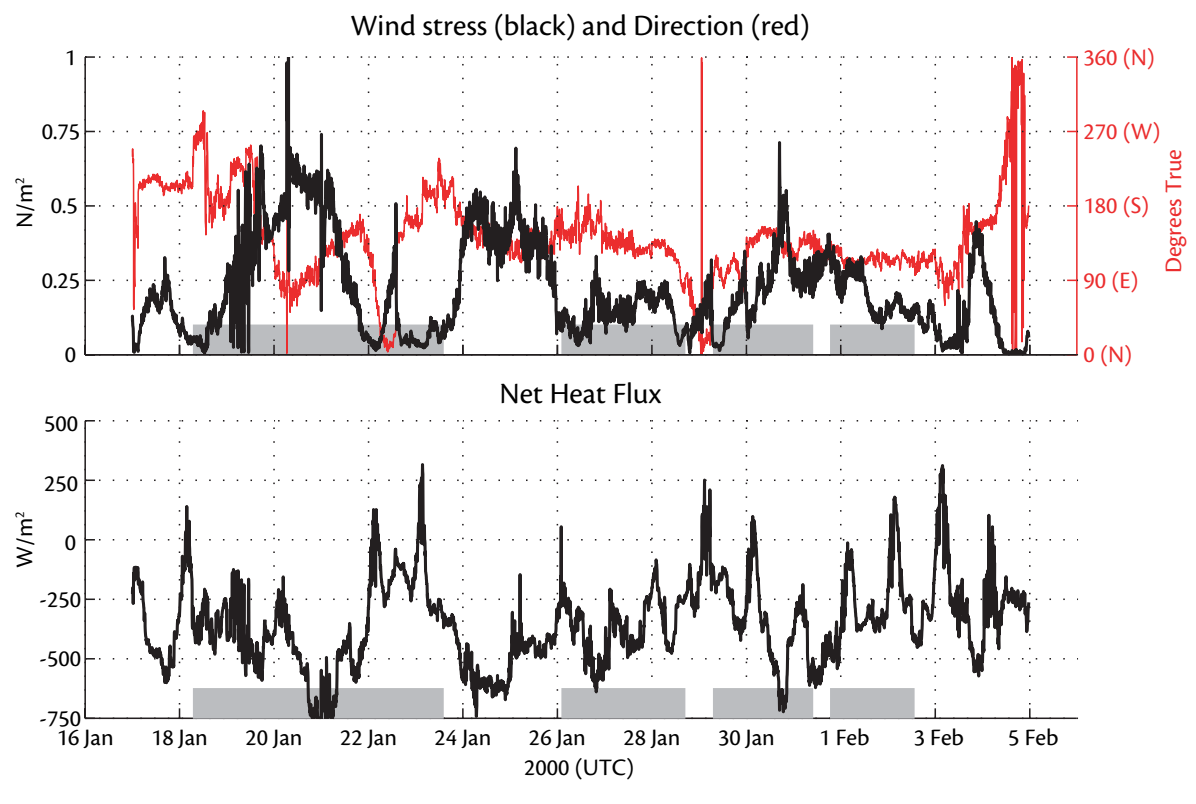

(b) MAY-JUNE 1999 JES SEASOAR CRUISE

Wind stress (black) and Direction (red)

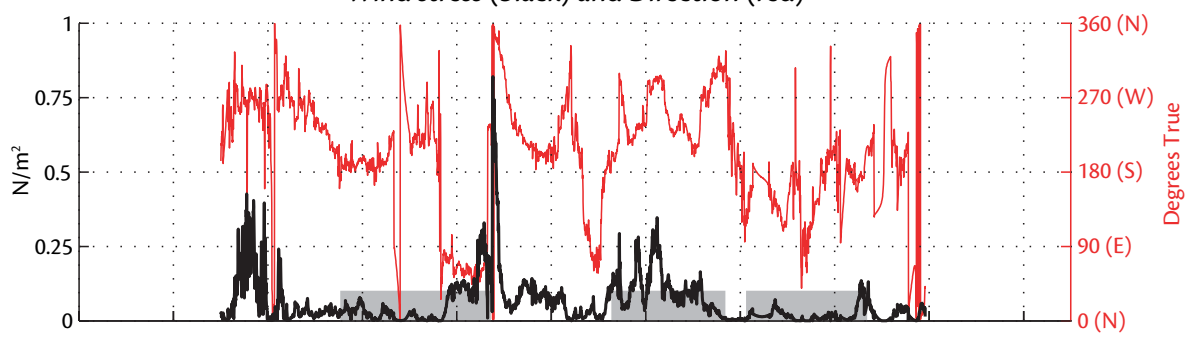

Net Heat Flux

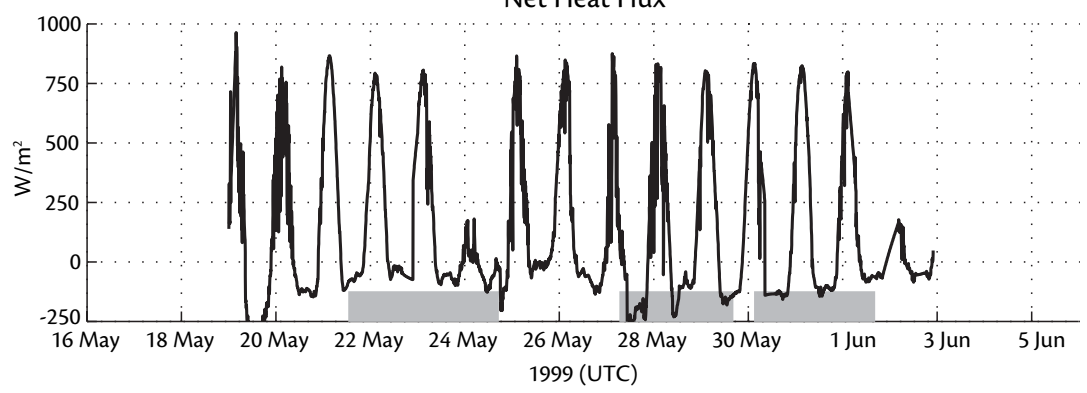

Figure 5. Wind stress, wind direction (toward), and net surface heat flux for the (a) January-February 2000 and (b) May-June 1999 R/V Roger Revelle SeaSoar cruises. Gray bars mark SeaSoar surveys of the Subpolar Front.

of Vladivostok where cold, dry Siberian air first encounters warmer Japan/East Sea waters (driving deep water formation, e.g., Talley et al., 2003), over the Subpolar Front, and also near the Japanese coast, where air-sea temperature contrasts can be large (Dorman et al., 2004). Net surface heat flux derived from an MM5 simulation (more information on this model is available at http://www. mmm.ucar.edu/mm5/mm5-home.html) of the 20 January 2000 cold-air outbreak (Figure 2) reflects these patterns, with large heat loss under outbreak pathways, where wind forcing is strongest. The results also show a distinct enhancement in heat loss associated with the Subpolar Front (between $39^{\circ}$ and $40^{\circ} \mathrm{N}$ ) driven by increased air-sea temperature difference as the cold Siberian air mass encounters the Tsushima Warm Current along the front's southern edge. Strong losses also occur in the warmer waters along the Japanese coast. Underway meteorological measurements collected at the Subpolar Front by R/V Roger Revelle captured three cold-air outbreaks during January-February 2000 (Figure 5a). Each outbreak (January 19-21 and 24-26, January 30-February 2) imposed strong south/southeastward winds and intense net surface heat loss over the front. Intensive SeaSoar surveys characterized subpolar front response during and immediately following these events.

During spring, the Subpolar Front experiences much weaker south/southwestward winds and net surface warming (Dorman et al., 2005). Underway meteorological measurements collected at the Subpolar Front during May-June 1999 revealed net warming dominated by short- and long-wave radiative fluxes 
and weak winds, typically with a component directed against the frontal jet (Figure 5b). During this period, three intensive surveys characterized frontal dynamics under weak forcing and documented the integrated effects of the previous winter's forcing.

\section{OCEAN RESPONSE}

Spring and Winter Subpolar Front

\section{Structure}

Contrasts between spring and winter Subpolar Front structure offer insights into the impact of strong atmospheric forcing. During spring, net surface warming stratifies the near-surface region, essentially eliminating the mixed layer (Figure 6, left column). Although Japan/East Sea surface-layer salinity typically decreases during summer, spring 1999 sections revealed enhanced salinity south of the Subpolar Front. This
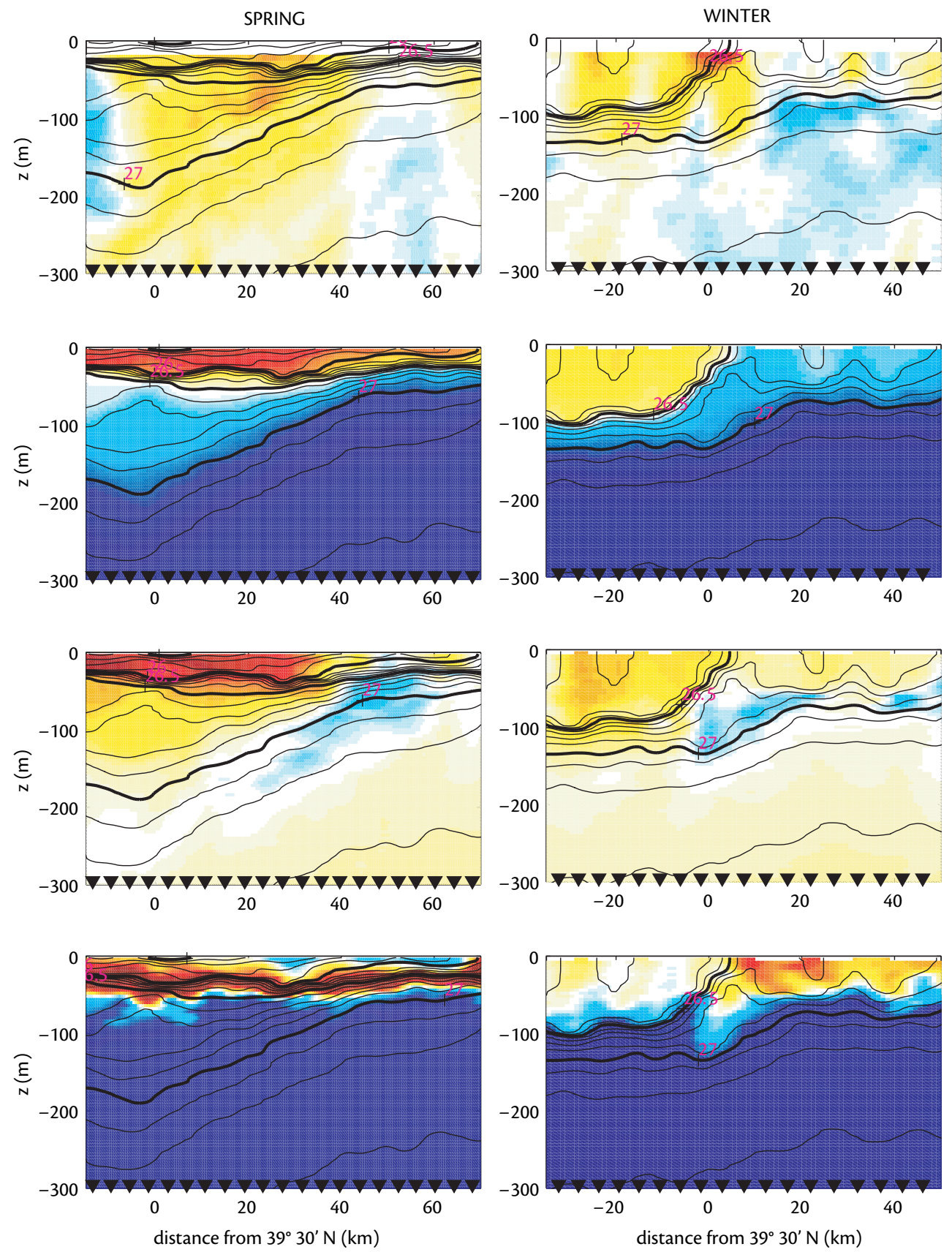
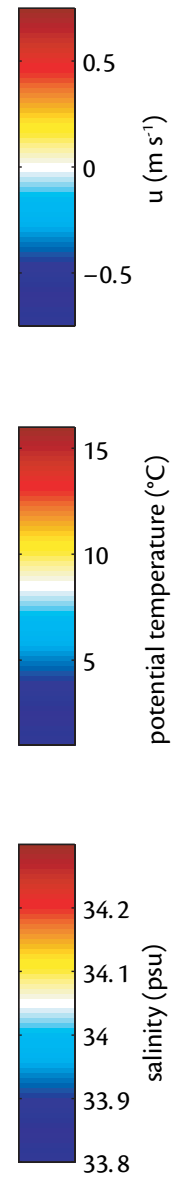

Figure 6. Sections across the Subpolar Front occupied in (left) May 1999 in and (right) January 2000. Sections depict (top to bottom) eastward velocity, potential temperature, salinity and $\log _{10}$ chlorophyll fluorescence, with potential density contoured at $0.1 \mathrm{~kg} \mathrm{~m}^{-3}$ intervals in the background. Marks along the bottom of each panel indicate SeaSoar profile positions. Strong wintertime atmospheric forcing produces 75-100-m-deep mixed layers, a sharp front with a narrow frontal jet and, beneath the front, lenses of weakly stratified, anomalously fresh water with high chlorophyll fluorescence. In the spring, radiative warming stratifies the surface layer and obscures the front. A large, anticyclonic eddy is embedded in the pycnocline south of the front. Waters within the eddy are weakly stratified and possess water-mass properties characteristic of the winter surface mixed layer north of the front, suggesting that wintertime frontal subduction might contribute to their formation. 
enhanced salinity could be the result of decreased riverine input as the Tsushima Warm Current source waters pass through the East China Sea. Due to the stratified cap, the front has only a weak surface expression. Below, the front is strong but broad, with the frontal jet spanning tens of kilometers in the horizontal and $100-200 \mathrm{~m}$ in the vertical. Although energetic vertical exchanges were not anticipated, a tongue of anomalously fresh water extends downward from the north side of the front. Hydrographic sections (not shown) revealed thin, fresh layers with elevated dissolved oxygen and chlorophyll fluorescence concentrations extending downward along the $27.0 \mathrm{~kg} \mathrm{~m}^{-3}$ isopycnal.

In contrast, the wintertime Subpolar Front exhibits strong lateral contrasts at scales of 5-10 km that support a narrow, submesoscale, surface-intensified frontal jet with strong lateral shear (Figure 6, right column). Strong wind mixing erodes the surface stratification to produce 75-100-m-deep mixed layers. Meanders and small-scale eddies impart energetic three-dimensional variability to the region surrounding the front (Figure 7). Although this frontal segment was selected because it was relatively straight, intensive SeaSoar surveys revealed a broad bend with complex flow patterns, including a large anticyclone along the northern boundary and a smaller anticyclone embedded within the front. The small anticyclones were found in several surveys, which characterized them as weakly stratified submesoscale $(10 \mathrm{~km})$ lenses embedded within the pycnocline near or south of the frontal interface (e.g., Figure 6, right column, $0-10 \mathrm{~km})$. Going from south to north across a lens, zonal velocity alternates from west to east, indicating an anticyclonic (clockwise) circulation. Water properties within the lenses (temperature, salinity, chlorophyll fluorescence) can be traced to outcroppings of the $26.5-27.0 \mathrm{~kg} \mathrm{~m}^{-3}$ isopycnals within mixed layers north of the front, suggesting formation by active subduction of nearsurface waters. In particular, plumes of elevated chlorophyll fluorescence that extend from the north-side mixed layer into the south-side pycnocline provide evidence of recent vertical exchange.

Springtime surveys also revealed large, weakly stratified lenses embedded in the south-side pycnocline between the 26.5$27.0 \mathrm{~kg} \mathrm{~m}^{-3}$ isopycnals (e.g., Figure 6, left column, $-10-10 \mathrm{~km}$ ). These density surfaces do not outcrop at the springtime front, isolating these large pycnostads (thick layers of uniform density) from the surface. Gordon et al. (2002) refer to these features as "intrathermocline eddies" and note that they possess water properties characteristic of winter-mixed layer waters at the $26.5-27.0 \mathrm{~kg} \mathrm{~m}^{-3}$ outcropping. Having these properties suggests formation by wintertime subduction at the Subpolar Front, perhaps as the integrated product of numerous forcing events.

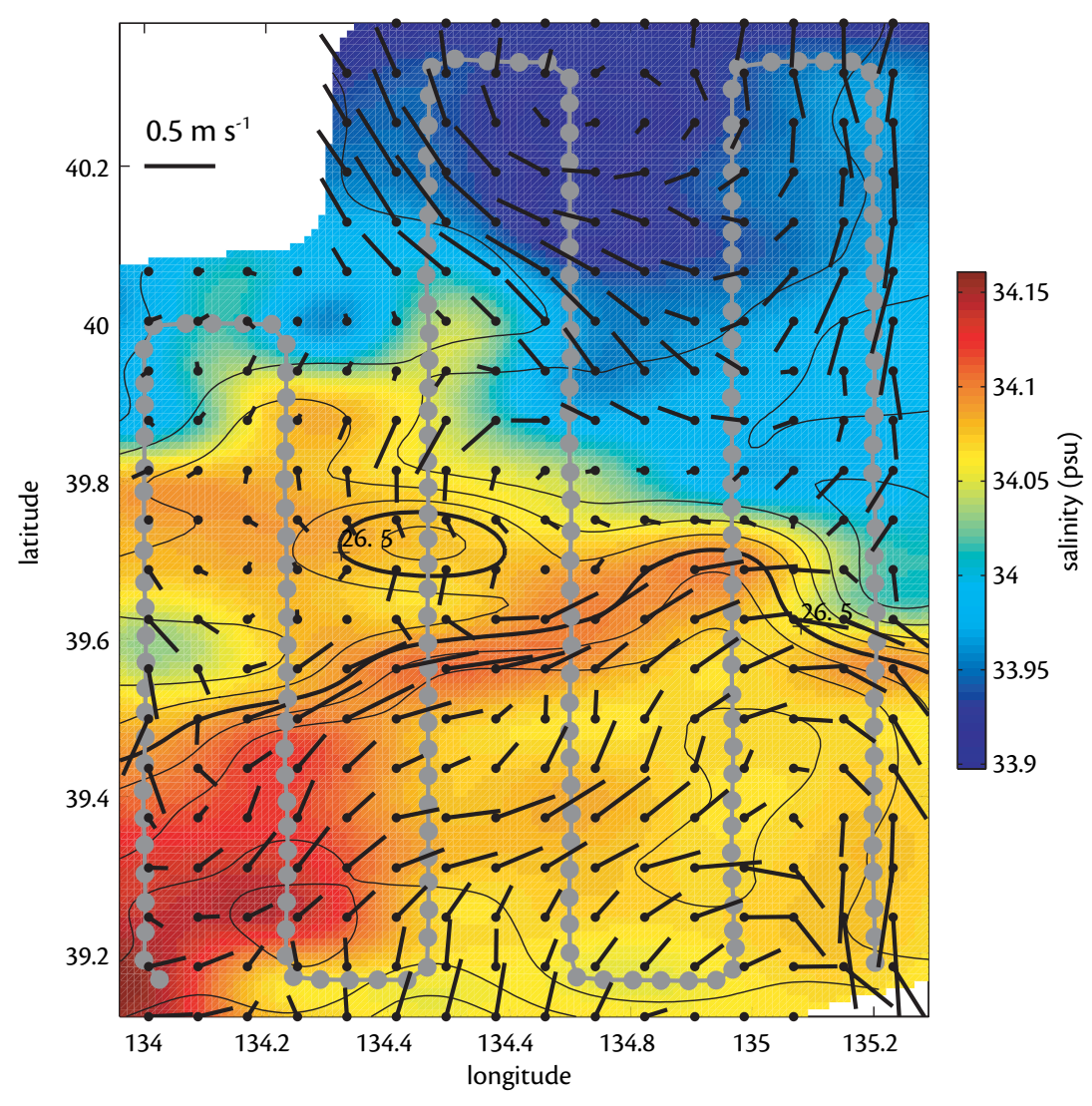

Figure 7. Objective map of salinity (color), potential density (contours), and velocity (vectors) at 22-m depth for the survey occupied during the January 29-31, 2000 event. The gray lines mark the SeaSoar survey track, with gray dots indicating profile locations, and black dots the tails of the velocity vectors. 


\section{Vertical Circulation at the Front}

Cross-front sections show evidence of strong vertical circulation at the wintertime front, raising several fundamental questions. What processes drive these vertical exchanges? Does strong atmospheric forcing play a critical role? Can high-resolution hydrographic and velocity data be used to quantify these circulation patterns?

\section{Mechanism for Frontal Vertical Circulation}

Vertical circulations arise at a front when the frontal jet is forced out of geostrophic balance. Owing to Earth's rotation, the Coriolis force associated with the velocity of the frontal jet prevents the tilted isopycnal surfaces of the front from slumping over and flattening. Processes that modify the frontal jet's velocity or the cross-front density gradient can disrupt this balance, potentially producing strong, small-scale vertical motions (Figure 8). The discussion that follows summarizes the processes depicted in Figure 8.

The classical mechanism for the generation of frontal vertical motions involves meanders and the three-dimensional structure of a front (Hoskins et al., 1978). Frontal meanders can drive confluent (diffluent) flow that compresses (expands) the cross-front density gradient. This effect tends to drive fluid down (up) the dense side of the front on the downstream (upstream) side of meander crests and can exist without atmospheric forcing.

Forcing by atmospheric buoyancy loss (cooling) can intensify vertical motions associated with frontal meanders. Cooling drives convective mixing that

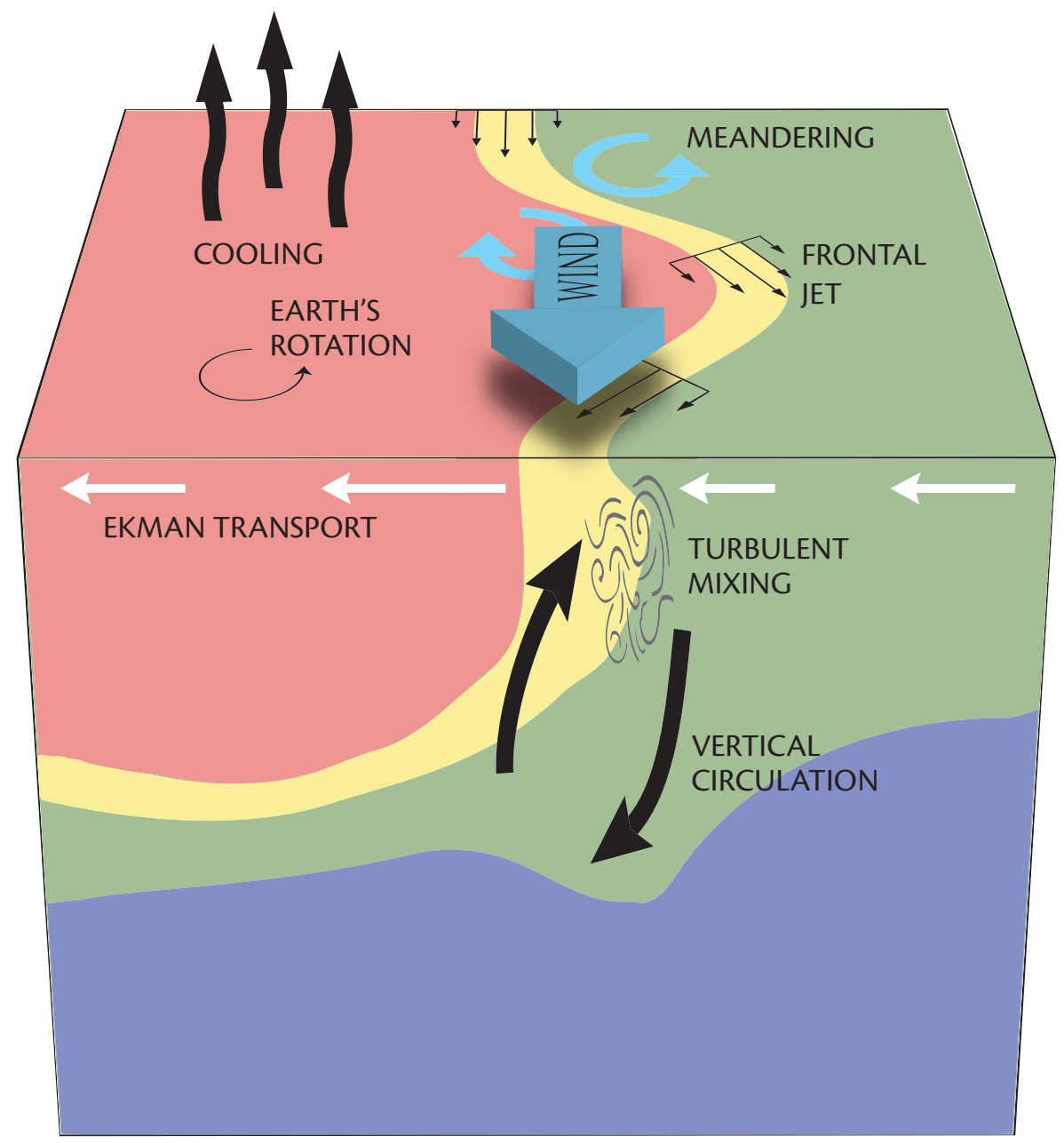

Figure 8. Schematic illustrating the various processes that can generate vertical circulation at a front. Frontal meandering can induce vertical motion irrespective of atmospheric forcing. Forcing by wind stress and/or surface cooling can drive turbulent mixing due to destabilizing buoyancy loss and, for along-front wind forcing, advection of denser water over light by Ekman flow. Lateral shear associated with the frontal jet can impart cross-front variability in Ekman transport, generating convergent/divergent flows. These processes break the geostrophic balance of the frontal jet and drive greatly enhanced vertical circulation.

modifies the frontal density gradient, further disrupting the geostrophic balance. In addition, convection reduces the vertical stratification. These two effects result in the enhancement of the frontal vertical circulation. The small-scale convective overturns (with width of the mixed-layer depth) superpose onto the frontal downdrafts and contribute to a strengthening of the vertical velocity (Yoshikawa et al., 2001).

The geostrophic balance can also be disrupted by wind stress. Along-front winds (i.e., in the direction of the frontal jet) drive Ekman transport that carries water from the dense side of the front to the less-dense side. In proximity of the front, Ekman flow advects denser water over light, which destabilizes the water column and drives turbulent mixing. This localized mixing modifies the crossfront density gradient and hence induces a vertical frontal circulation with downdrafts on the dense side of the front and 
updrafts along the outcropping frontal

isopycnal (Thomas and Lee, 2005).

Wind forcing can also drive vertical motions through convergent/divergent Ekman transport (i.e., through Ekman pumping/suction). On large spatial scales, Ekman pumping arises because of wind-stress curl. On submesoscale frontal scales, Ekman pumping can arise even if the wind stress is spatially uniform (Stern, 1965; Niiler, 1969). The strength of the Ekman transport is determined by the magnitude of the wind stress and the net rotation of the fluid, such that the stronger the rotation, the weaker the transport. On large scales and for weak currents, the net rotation of the fluid is set by Earth's rotation. On frontal scales, both Earth's rotation and the strong lateral shears associated with the frontal jet contribute to the fluid's net rotation. The lateral shear of the frontal jet is such that on the dense (light) side
If the wind is blowing down (up) the jet, the Ekman transport at the center of the frontal jet is divergent (convergent) and results in upwelling (downwelling).

\section{Inferring the Vertical Circulation at} the Subpolar Front

Vertical velocities are typically inferred

from solutions to a model that assumes that frontal vertical circulation is entirely driven by frontal meandering (e.g., Pollard and Regier, 1992; Rudnick, 1996). These models lack forcing and thus neglect the effect of buoyancy loss, turbulent mixing, and Ekman dynamics, which may play significant roles in regions of strong atmospheric forcing such as the wintertime Japan/East Sea. A method for inferring the vertical velocity that combines three-dimensional hydrographic and velocity observations with a model that allows for turbulent mixing and Ekman effects, as well

...results suggest that atmospheric

forcing can significantly intensify

vertical circulation, and thus

subduction rates, at upper-ocean fronts

of the front, the net spin of the fluid is greater (less) than the spin due to Earth's rotation. This shear of the frontal jet reduces (amplifies) the Ekman transport within and to the dense (light) side of the frontal jet and hence drives vertical motions (Figure 8). The sense of this vertical circulation depends on the direction of the wind stress relative to the frontal jet. as meandering of the front (Thomas and Lee, in preparation), addresses the demands imposed by strongly forced fronts. An example of vertical circulation inferred using this method (Figure 9) depicts a strong frontal downdraft coincident with a streamer of weakly stratified fresh water extending downward from the surface, a clear indicator of active subduction. This method diagnoses vertical velocities of $1-2 \mathrm{~mm} \mathrm{~s}^{-1}$ (100-200 $\left.\mathrm{m} \mathrm{day}^{-1}\right)$ at the front, nearly ten times larger than would be inferred by neglecting atmospheric forcing and assuming that frontal meanders were the sole driver of vertical exchange. Mixing associated with Ekman-driven convection acts to balance vertical buoyancy flux produced by these large vertical velocities. Although the example section (Figure 9) depicts velocities crossing isopycnals, which are perhaps responsible for the weakly stratified region beneath and south of the frontal outcrop, vertical circulation estimated for other subpolar front sections often occurs on slantwise paths that tend to align along isopycnal slopes. Within the front's outcropping isopycnals, a recirculation cell centered at $\mathrm{y} \approx 13 \mathrm{~km}$ and $\mathrm{z} \approx-60 \mathrm{~m}$ upwells stratified water from the pycnocline. Observed chlorophyll fluorescence patterns provide a striking, if qualitative, match with the inferred vertical circulation (Figure 9, left panel). A plume of high chlorophyll fluorescence coincides with the frontal downdraft, while fluid with low chlorophyll fluorescence appears to be drawn up from the pycnocline and recirculated within the frontal outcrop. In addition to providing evidence supporting the inferred vertical circulation, this result also points to the potential impact of such strong vertical exchanges on the structure of submesoscale biooptical features often observed at fronts (e.g., Barth et al., 2001).

\section{CONCLUSIONS}

High-resolution, three-dimensional surveys of the Japan/East Sea Subpolar Front conducted during Siberian cold- 


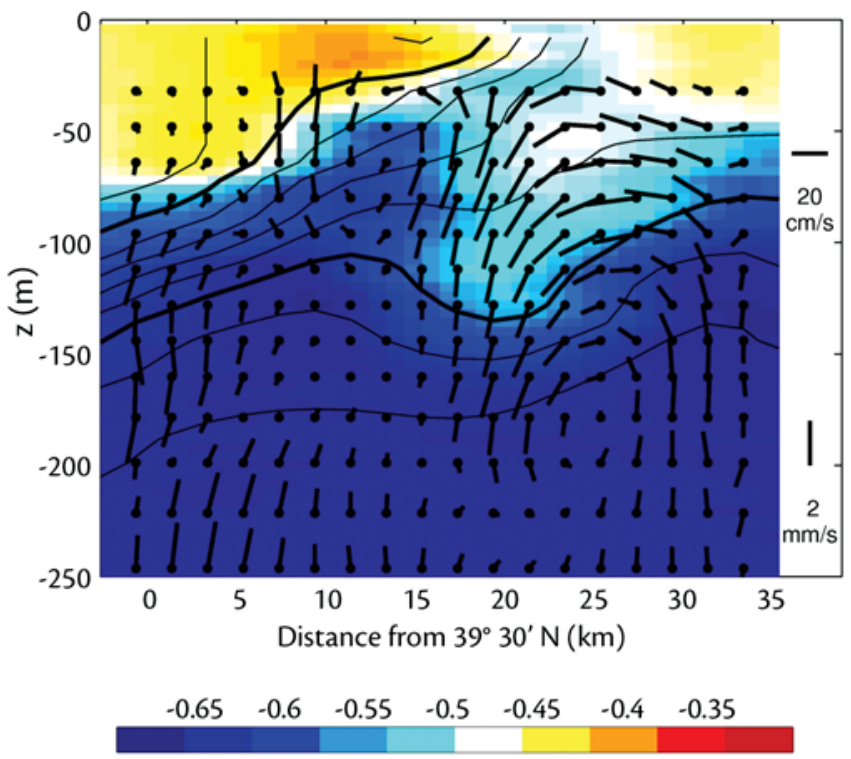

$\log _{10}[$ ch. flourescence (volts)]
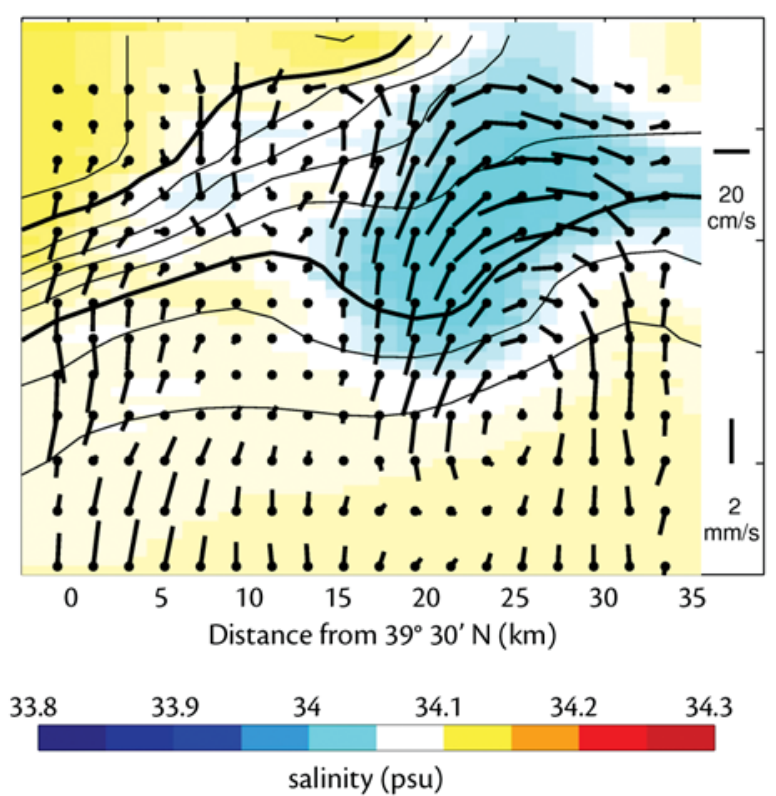

Figure 9. Vectors of the inferred vertical circulation at the Subpolar Front superposed on (left) chlorophyll fluorescence and (right) salinity for a section from the 26-29 January 2000 survey. Dots indicate the tail of the velocity vector, isopycnals are contoured at $0.1 \mathrm{~kg} \mathrm{~m}^{-3}$ intervals, and the thick contours denote the 26.5 and $27.0 \mathrm{~kg} \mathrm{~m}^{-3}$ isopycnal surfaces. The horizontal component of the vector is the meridional velocity that is not in geostrophic balance. The strong frontal downdraft just to the north of the front has vertical velocities of up to $200 \mathrm{~m}_{\text {day }}{ }^{-1}$ and subducts weakly stratified, relatively fresh water with high chlorophyll fluorescence.

air outbreaks reveal strong frontal vertical circulation and subduction. Intense wind and buoyancy forcing associated with cold-air outbreaks drive stronger vertical circulation than is expected if they were driven solely by frontal meanders. Cold-air outbreaks force the Subpolar Front through strong surface cooling and intense down-front winds. Surface cooling drives convective overturning, which disrupts geostrophic balance and weakens stratification, resulting in enhanced vertical exchange. Downfront winds drive Ekman flows that are modulated by lateral shears associated with the frontal jet. Ekman advection carries dense waters over light, driving overturning and intensifying vertical circulation. Both of these processes inject weakly stratified wintertime mixed-layer waters from the Subpolar Front into the pycnocline, forming submesoscale anticyclones reminiscent of those produced in numerical simulations (e.g., Spall, 1995). Integrated over an entire winter of episodic forcing by cold-air outbreaks, these processes likely produce the large, subsurface layers of weakly stratified fluid observed in springtime at various locations south of the front (Gordon et al., 2002).

These results suggest that atmospheric forcing can significantly intensify vertical circulation, and thus subduction rates, at upper-ocean fronts. Mode waters are found on the equatorward side of major ocean fronts, including the Gulf Stream in the Atlantic, the Kuroshio in the Pacific, and the Subantarctic front in the Southern Ocean (Hanawa and Talley,
2000). Each of these fronts experiences strong wind forcing with a significant down-front component. If these major fronts share similar dynamics with the Japan/East Sea Subpolar Front, atmospheric forcing by down-front winds and surface cooling, as described above, may play significant roles in driving subduction and mode-water formation in the global ocean.

Strong vertical exchanges associated with atmospherically forced fronts also impact biological variability. Patterns of chlorophyll fluorescence trace the inferred vertical circulation at the front. Plumes of elevated fluorescence extend downward in downdraft regions and corresponding plumes of low-chlorophyll waters follow updrafts from the deep toward the surface (Figure 9). 
Turbulent mixing and vertical advection should also transfer nutrients from the pycnocline into the euphotic zone, enhancing nutrient availability near the front. Although further investigation requires detailed nutrient concentration and biological measurements, chlorophyll-fluorescence sections typically reveal elevated concentrations at and north of the frontal interface. It seems likely that energetic submesoscale vertical circulation would drive enhanced primary and secondary productivity near forced upper-ocean fronts.

Three-dimensional numerical simulations of idealized representations of the Subpolar Front forced by either down-front winds or cooling aid in the dynamical interpretation of these observations. The simulations are extensions of the modeling efforts of Yoshikawa et al. (2001) and Thomas (2005) and are aimed at quantifying the contributions of wind stress, heat loss, and meandering to the vertical circulation and subduction of weakly stratified waters at the front. An illustrative solution from the cooling-forced simulations is shown in Figure 10. The simulations reveal that both cooling and wind forcing result in an enhancement of vertical circulation relative to meander-driven subduction, similar to what was concluded from the observations. In both runs, intrathermocline eddies form that are filled with subducted frontal water and that have structures reminiscent of the lenses of weakly stratified fluid observed in the spring. Unlike the actual Subpolar Front, the simulations were forced by cooling and wind stress separately. Future research will employ numerical experi- ments with combined down-front wind and buoyancy forcing to assess the relative roles of wind- and cooling-driven mixing on the formation and subduction of weakly stratified water at the front and subsequent transport away from the front.

\section{ACKNOWLEDGMENTS}

We thank Drs. Robert Arnone (Naval Research Laboratory, Stennis Space Center), Robert Beardsley (Woods Hole Oceanographic Institution), Clive Dorman (Scripps Institution of Oceanography), Burton Jones (University of Southern California), and Shuyi Chen (Rosenstiel School of Marine and Atmospheric Science, University of Miami) for providing data used in this paper and for collegial discussion and collaboration throughout the Japan/East Sea
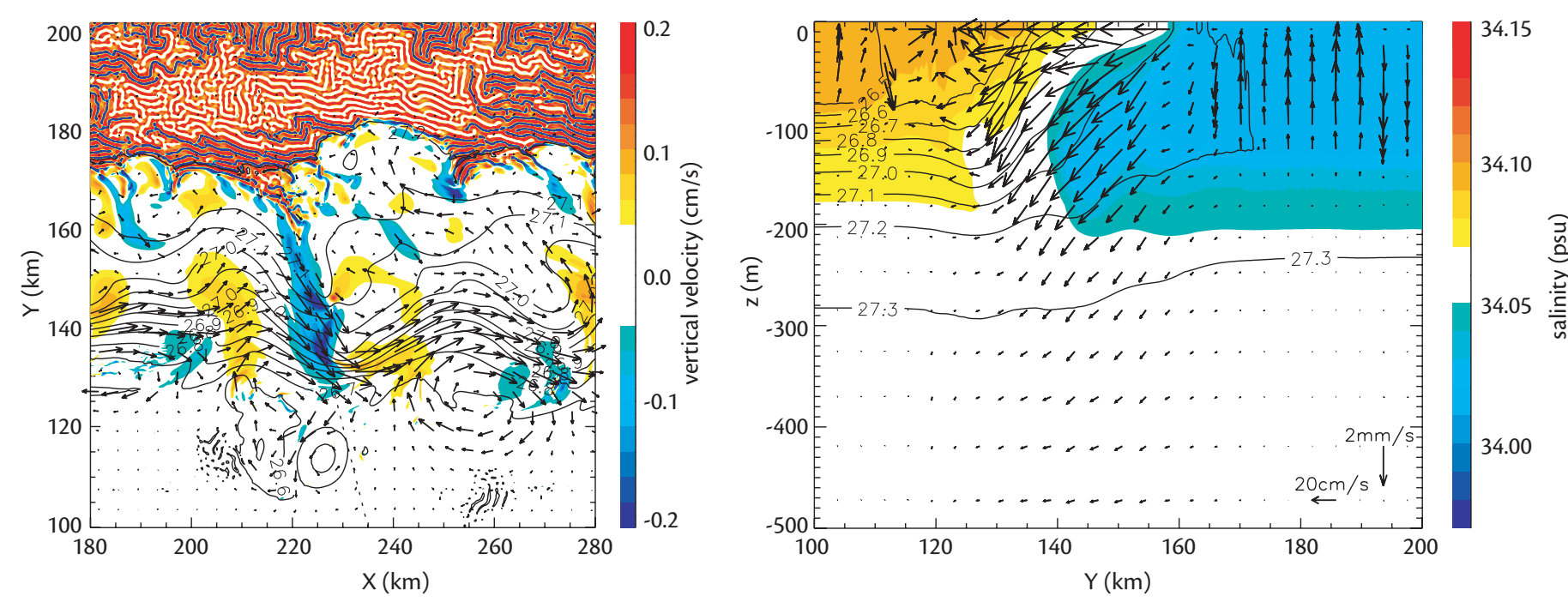

Figure 10. Solution from a numerical simulation of an idealized subpolar front forced by cooling. (left) Vertical velocity (colors), density (contours), and horizontal velocity (vectors) at $\mathrm{z}=-100 \mathrm{~m}$. Near the front, downwelling (upwelling) is found on the down (up)-stream side of meander crests. Small-scale convective overturns (which are explicitly resolved in the model and that give rise to the labyrinthine structure in the vertical velocity north of the front) drive turbulent mixing that enhances the frontal vertical circulation. (right) A cross-front section taken along the dashed line strikes through a strong downdraft. Flow in the downdraft (vectors) is nearly parallel to the outcropping isopycnals and subducts low-salinity water (colors) down the dense side of the front. 
program. The hard work of Frank Bahr, Jerry Dean, Paul Fucile, Al Gordon, Craig Marquette, Matthew Ragan, Zhihong Zheng, Rick Gould, and Paul E. La Violette made these observations possible. Captain Chris Curl and the crew of the R/V Roger Revelle provided exceptional, enthusiastic support in difficult win-
Gordon, A.L., C.F. Giulivi, C.M. Lee, A. Bower, H.H. Furey, and L. Talley. 2002. Japan/East Sea intrathermocline eddies. Journal of Physical Oceanography 32:1,960-1,974.

Hanawa, K., and L. Talley. 2000. Mode waters. In: Ocean Circulation and Climate, J. Church and G. Siedler, eds., Academic Press, Burlington, MA.

Hoskins, B.J., I. Draghici, and H.C. Davies. 1978. A new look at the $\omega$-equation. Quarterly Journal of the Royal Meteorology Society 104:31-38.

Isoda, Y. 1994. Interannual SST variations to the north
Future research will...assess the relative roles of wind-and cooling-driven mixing on the formation and subduction of weakly stratified water at the front and subsequent transport
away from the front.

ter conditions. Comments from two anonymous reviewers helped improve the manuscript. The Japan/East Sea project was supported by the Office of Naval Research Physical Oceanography program under grant N00014-98-10370. The National Science Foundation supported Leif Thomas under grant OCE-03-51191. 四

\section{REFERENCES}

Barth, J.A., T.J. Cowles, and S.D. Pierce. 2001. Mesoscale physical and bio-optical structure of the Antarctic Polar Front near $170 \mathrm{~W}$ during austral spring. Journal of Geophysical Research 106:13,879$13,902$.

Dorman, C.E., R.C. Beardsley, N.A. Dashko, C.A. Friehe, D. Kheilf, K. Cho, R. Limeburner, and S.M. Varlamov. 2004. Winter marine atmospheric conditions over the Japan Sea. Journal of Geophysical Research 109 (C12011): doi:10.1029/2001JC001197.

Dorman, C.E., R.C. Beardsley, R. Limeburner, S.M. Varlamov, M. Caruso, and N.A. Dashko. 2005. Summer atmospheric conditions over the Japan/ East Sea. Deep-Sea Research 52:1,393-1,420. and south of the Polar Front in the Japan Sea. $L a$ Mer 32:285-294.

Isoda, Y., S. Saitoh, and M. Mihara. 1991. SST Structure of the Polar Front in the Japan Sea. In: Oceanography of Asian Marginal Seas, K. Takano, ed., Elsevier Science Publisher, Amsterdam, The Netherlands, 103-112.

Joyce, T.M., J.R. Luyten, A. Kubryakov, F.B. Bahr, and J.S. Pallant. 1998. Meso- to large-scale structure of subducting water in the subtropical gyre of the eastern North Atlantic Ocean. Journal of Physical Oceanography 28:40-61.

Kajiura, K., M. Tsuchiya, and K. Hidaka. 1958. The analysis of oceanographical condition in the Japan Sea, In: Report on the Development of Fisheries Resources in the Tsushima Warm Current, v. 1, Tokyo Fish. Agency, Tokyo, Japan, 158-170.

Kawamura, H., and P. Wu. 1998. Formation mechanism of Japan Sea Proper Water in the flux center off Vladivostok. Journal of Geophysical Research 103:21,611-21,622.

Kim, K., and J.Y. Chung. 1984. On the salinity-minimum and dissolved oxygen-maximum layer in the East Sea (Sea of Japan). In: Ocean Hydrodynamics of the Japan and East China Seas, T. Ichiye, ed., Elsevier Science Publisher Amsterdam, The Netherlands, 55-65.

Niiler, P. 1969. On the Ekman divergence in an oceanic jet. Journal of Geophysical Research 74:7,048-7,052. Park, K.-A., J.Y. Chung, and K. Kim. 2004. Sea surface temperature fronts in the East (Japan) Sea and temporal variations. Geophysical Research Letters 31(L07304), doi:10.1029/2004GL019424.

Pollard, R.T., and L.A. Regier. 1992. Vorticity and vertical circulation at an ocean front. Journal of Physical Oceanography 22:609-625.

Rudnick, D.L. 1996. Intensive surveys of the Azores Front: 2. Inferring geostrophic and vertical velocity fields. Journal of Geophysical Research 101:16,29116,304 .

Rudnick, D.L., and J.R. Luyten. 1996. Intensive surveys of the Azores Front: 1. Tracers and dynamics. Journal of Geophysical Research 101:923-939.

Scotti, A.D. 2005. Orographic effects during winter cold-air outbreaks over the Sea of Japan (East Sea): Results from a shallow-layer model. Deep-Sea Research 52:1,705-1,725.

Spall, M.A. 1995. Frontogenesis, subduction and crossfront exchange at upper ocean fronts. Journal of Geophysical Research 100:2,543-2,557.

Spall, M.A., R.A. Weller, and P.W. Furey. 2000. Modeling the three-dimensional upper ocean heat budget and subduction rate during the Subduction Experiment. Journal of Geophysical Research 105:26,151-26,166.

Stern, M.E. 1965. Interaction of a uniform wind stress with a geostrophic vortex. Deep-Sea Research 12:355-367.

Talley, L.D., V. Lobanov, V. Ponomarev, A. Salyuk, P. Tishchenko, I. Zhabin, and S.C. Riser. 2003. Deep convection and brine rejection in the Japan Sea. Geophysical Research Letters 30(1159), doi:10.1029/ 2002 GL016451.

Thomas, L.N. 2005. Destruction of potential vorticity by winds. Journal of Physical Oceanography 35:2,457-2,466.

Thomas, L.N., and C.M. Lee. 2005. Intensification of ocean fronts by down-front winds. Journal of Physical Oceanography 35:1,086-1,102.

Thomas, L.N., and C.M. Lee. In preparation. Inverse method for determining mesoscale and submesoscale vertical circulation with application to the Subpolar Front of the Japan/East Sea. Journal of Physical Oceanography.

Yoon, J.-H., and H. Kawamura. 2002. The formation and circulation of the intermediate water in the Japan Sea. Journal of Oceanography 58:197-211.

Yoshikawa, Y., T. Awaji, and K. Akitomo. 1999. Formation and circulation processes of intermediate water in the Japan Sea. Journal of Physical Oceanography 29:1,701-1,722.

Yoshikawa, Y., K. Akitomo, and T. Awaji. 2001. Formation process of intermediate water in baroclinic current under cooling. Journal of Geophysical Research 106:1,033-1,051. 